\section{EXPOSICIÓN MAGISTRAL \\ Movimientos sociales y redes de comunicación Una aproximación a partir de la movilización de jóvenes peruanos en contra de la ley Pullpín ${ }^{1}$}

\author{
Social movements and communication network \\ An approach from the mobilization of young Peruvians \\ against the "Pulpin" law
}

Jorge Acevedo Rojas Comunicador social y educador. Especialista en diseño, gestión y evaluación de proyectos de comunicación. Coordinador de la Especialidad de Comunicación para el Desarrollo de la PUCP.

\title{
RESUMEN
}

El artículo explora y analiza el rol de las redes digitales de comunicación, como instrumento y, a la vez, como espacio social de expresión y articulación de voluntades en el marco de las movilizaciones sociales en contra de la denominada ley Pulpín, entre diciembre de 2014 y enero de 2015. La norma fue impulsada por sectores empresariales con el apoyo del gobierno, para promover el acceso de los jóvenes al mercado laboral, pero suscitó la protesta social por considerarla atentatoria contra los derechos laborales. Miles de jóvenes y otros grupos sociales marcharon por calles y plazas de Lima y otras ciudades del país; desarrollaron un uso intensivo de las redes digitales de comunicación e información para coordinar, convocar y expresar sus puntos de vista sobre la ley y la política de promoción del empleo, y lograron, también, una presencia importante en medios de comunicación, convirtiéndose en un actor social con capacidad de interlocución política.

Palabras clave: Movimientos sociales, redes de comunicación, jóvenes, política

\section{ABSTRACT}

The article explores and analyzes the role of digital communication networks, as well as instrument and social spaces for build wills, during the social mobilization against the law called "Pulpín", between December 2014 and January 2015. The law was promoted by economic groups with government's support, in order to promote access to the labor market to young people, but it raised social protest, because the law removed some labor rights. Thousands of young people and other social groups marched through streets and squares of Lima and other cities, and developed an intensive use of digital communication

\footnotetext{
1 El término Pulpín es parte de la jerga que en el Perú es utilizada para referirse peyorativamente a adolescentes y jóve-
} nes considerados ingenuos, fácilmente manipulables. 
12 networks to coordinate, convene and express their points of view about the law and policies to promote employment, and also they achieved a significant presence in the media, becoming a social actor with capacity for political dialogue.

Keywords: Social movements, communication networks, young people, politics

\section{Los movimientos sociales como acción colectiva}

Los movimientos sociales son formas de acción colectiva que emergen de las contradicciones inherentes a las sociedades y comportan una importante capacidad de transformación social. Se trata de "sistemas de prácticas sociales contradictorias que controvierten el orden establecido" (Castells 2000: 3). Tienen como origen el malestar y las reivindicaciones de diversos sectores de la sociedad, pero se constituyen en movimientos en tanto las demandas se transforman en voluntad y acción política para impulsar cambios.

Históricamente, el conflicto de clase (por el control y la distribución de la riqueza) ha sido y continúa siendo uno de los factores fundamentales que explica la emergencia de los movimientos sociales. Sin embargo, en las últimas décadas ha emergido con mayor vigor y presencia pública local e internacional un conjunto de colectivos sociales cuyos ámbitos de controversia y reivindicación tienen que ver con valores e instituciones sociales que son transversales a las clases sociales: los movimientos ecologistas, feministas, defensores de los animales, entre otros.

Para Tilly, los movimientos sociales constituyen una "versión particular de la contienda política" (2010: 21). Los movimientos proponen un conjunto de reivindicaciones de carácter económico, social y cultural, que colisionan con los intereses de grupos sociales que ejercen formas institucionales de dominación. Según Tilly, son una especie de síntesis de tres elementos: un esfuerzo organizado de carácter colectivo, que tiene como finalidad trasladar una determinada problemática y reivindicación a las autoridades o representantes; el despliegue combinado de diversas formas de acción política: conformación de coaliciones, marchas, comunicaciones de carácter público, reuniones y asambleas, participación en medios de comunicación; y expresiones públicas de compromiso, dimensión numérica y cohesión internas.

Los movimientos sociales involucran a los Estados y los gobiernos, pues por acción u omisión de estos en ciertos campos controversiales de política pública es que se abren oportunidades para la emergencia y despliegue de diversas formas de acción colectiva.

Desde la perspectiva de Castells (2000), los movimientos sociales urbanos tienen como características principales el hecho de que expresan un tipo de contenido social sin ambigüedad, en el sentido que los intereses en juego confrontan directamente; tienen, generalmente, una base social de carácter homogéneo; logran construir un nivel básico de organización política; y desarrollan con eficacia acciones de coordinación, convocatoria y movilización.

Los movimientos sociales conllevan tres tipos de reivindicaciones (Tilly, 2010). Las reivindicaciones, que pueden ser interdependientes, se agrupan en: programáticas, que consisten en el apoyo o la oposición abierta a acciones sobre los objetos o asuntos de las reivindicaciones de los movimientos sociales; identitarias, que implican el reconocimiento y la afirmación de un colectivo cohesionado que demanda ser tomado en cuenta en el debate público y las decisiones políticas; y de posición, aquellas reivindicaciones que afirman vínculos y similitudes con otros actores sociales y políticos.

Los colectivos sociales tienen dos niveles de acción. El primero es de carácter organizativo, muchas veces interno y poco visible, que supone el desarrollo de una serie de estrategias y acciones orientadas al fortalecimiento y cohesión del grupo impulsor de la acción colectiva. El segundo nivel de intervención tiene un carácter visible, manifiesto, y supone la autorepresentación y la intervención reactiva y/o propositiva de los movimientos en el espacio público contemporáneo, a través de la producción y diseminación de discursos que tienen como finalidad ejercer presión, negociar o convencer.

Los movimientos sociales despliegan en el ámbito de la esfera pública un amplio repertorio de formas de acción colectiva: marchas y otras modalidades de intervención pública en las calles y 
plazas de las ciudades, ocupan también diversas vías interurbanas; diseñan y ejecutan campañas de información y comunicación orientadas a hacer visibles las problemáticas y sus propuestas, tanto en espacios físicos como virtuales como las redes Facebook y Twitter, convertidas en importantes plataformas en las que discurren los discursos e intercambios sociales y políticos de hoy.

Para Cohen y Arato (2000), la acción colectiva implica formas de asociación, organización y de intervención estratégica propias de una sociedad civil moderna, pluralista. El contexto social contemporáneo, en el que emergen y actúan los llamados nuevos movimientos sociales, comprende los espacios públicos tradicionales, los medios de comunicación masiva y, más recientemente, las redes digitales; las garantías constitucionales (libertad de asociación, de expresión y de reunión), también las instituciones políticas representativas y los sistemas legales, ámbitos en los cuales actúan los movimientos sociales tratando de incidir en decisiones políticas o en la generación de cambios socioculturales más profundos y duraderos, en los valores y las instituciones sociales.

Existen algunos factores importantes que, desde la perspectiva de Tilly (2010), estimulan la formación y emergencia de movimientos sociales. Destaca, por ejemplo, la pérdida de capacidad de decisión de los Estados sobre temas económicos nacionales e internacionales en el contexto de la globalización capitalista. Asimismo, los procesos de democratización en términos de la afirmación de derechos y libertades alientan la formación de movimientos sociales aunque estos, a su vez, impactan de manera recíproca en la democracia. Y la crisis de representatividad, expresada en la ruptura de vínculos entre representados y representantes, constituye un factor que desencadena formas de acción colectiva que desborda los canales políticos tradicionales.

Finalmente, respecto a la direccionalidad del cambio de los movimientos sociales, podría establecerse como rutas posibles el declive o desaparición del movimiento, o más bien su transformación en formas institucionales de organización y acción (partidos políticos, organizaciones de cabildeo), perdurabilidad y auge (Tilly 2010: 287288). La direccionalidad de un movimiento implica también ámbitos o escenarios de acción de carácter local, regional, nacional e internacional, en tanto buena parte de los objetivos de las reivindicaciones sociales tienen una dimensión planetaria: pobreza, cambio climático, desigualdad de género.

\section{Redes digitales de comunicación ¿Instrumentos o arenas de lucha política?}

En articulación con los espacios tradicionales de acción social y política, que incluyen a los medios de comunicación convencionales: prensa, radio y televisión, en las tres últimas décadas, las llamadas nuevas tecnologías de información y comunicación han transformado significativamente la dimensión y dinámicas de producción y consumo de contenidos en el ámbito global. El espacio público configurado por las redes multimedia constituye la arena principal de la política contemporánea (Castells, 2009).

El desarrollo de las redes multimedia (Internet y formas de comunicación móvil) ha ampliado de manera significativa la capacidad individual y colectiva para producir e intercambiar significados sobre diversos órdenes de la vida social y política. Las redes multimedia son un espacio de autorepresentación, individual y colectiva, a través de la configuración de perfiles personales e institucionales. Y constituyen un ámbito en el cual se construyen y cultivan relaciones sociales, en conexión o no necesariamente, con las relaciones cara a cara. Así, el ámbito de las redes multimedia se va consolidando como un espacio de sociabilidad, de construcción y afirmación de vínculos entre personas y colectivos sociales.

Las modernas tecnologías de información y comunicación, en constante cambio, se han insertado en la vida cotidiana, en el mundo privado y en la vida pública de las sociedades. "Los medios digitales ya no son extraños sino que los hemos incorporado a nuestra vida diaria sin darnos cuenta" (Horst 2015: 16). Y son las nuevas generaciones, que han nacido y se socializan en el mundo de la comunicación digital, quienes por lo general tienen un mayor conocimiento práctico del uso y aprovechamiento de las diversas herramientas de comunicación.

Asimismo, la ampliación de las posibilidades de acceso y producción de contenidos en las redes multimedia ha posibilitado que diversas organi- 
14 zaciones y colectivos de sociedad civil, que hace tres décadas estaban en gran medida excluidas del espacio mediático, potencien su capacidad de coordinación, articulación y visibilidad de sus reivindicaciones y propuestas de cambio (La Rosa, 2014).

Incluso, en tanto se ha convertido en un espacio de sociabilidad que coexiste y se vincula con otros espacios de interacción social, el surgimiento de los movimientos sociales tiene como escenario el ámbito de las redes de comunicación digital. A las formas de acción colectiva off-line (en espacios físicos), se ha articulado el activismo social on-line, adquiriendo incluso una dinámica propia, interdependiente.

Desde la perspectiva de Castells (2015), Internet y las redes de comunicación han posibilitado la emergencia de los movimientos sociales más importantes de los últimos años en el mundo. Destacan, en principio, las movilizaciones en protesta contra los gobiernos que han generado formas de salvataje del sector financiero, principal responsable de la crisis económica mundial desencadenada en el año 2008, y que trasladaron el costo de la debacle económica a amplios sectores sociales a través del recorte de presupuestos destinados a las áreas de desarrollo y protección social.

Entre las movilizaciones más significativas, cabe destacar la acción de los Indignados en España, cuyo hito fundacional se produjo el 15 de mayo de 2011, y el movimiento Occupy Wall Street, que emergió en setiembre del mismo año. Estos y otros colectivos sociales surgidos casi simultáneamente en diversos países fueron portadores de una crítica frontal al sistema económico neoliberal, considerado el gran causante de la crisis. Pero las movilizaciones masivas expresaron también la crisis de representatividad que profundiza la distancia entre los problemas, necesidades y anhelos de los ciudadanos y las decisiones que toman los gobiernos. Las movilizaciones fueron portadoras de un vigoroso reclamo por nuevas formas de expresión y deliberación ciudadana, una demanda sentida por la redefinición de la representación política que aparece como desfasada (Castells, 2015).

Las nuevas formas de acción colectiva en la era de Internet no solo se produjeron en Europa y Estados Unidos donde tuvieron como motivo principal de protesta las decisiones que gobiernos democráticos tomaron en el contexto de la crisis económica mundial. En otra región del mundo, cientos de miles de personas encontraron en las redes multimedia y la comunicación móvil, el escenario propicio y las herramientas necesarias para impulsar marchas y otras formas de manifestación en favor de la democratización de sus sociedades. Entre fines del año 2010 y comienzos de 2011, se produjo el fenómeno social y político conocido como la Primavera Árabe, que involucró a Túnez, Egipto, Libia, Yemen y Siria, entre otros países. Y si bien los procesos de democratización han sido contradictorios, con avances y retrocesos, esta importante región del mundo ya no es la misma a causa de un estallido social en cuya base la comunicación digital desempeñó un rol significativo.

América Latina no ha sido la excepción en términos de la emergencia de movimientos sociales en cuyos orígenes y despliegue las redes multimedia han tenido un rol significativo. En Chile, uno de los países con mayor nivel de institucionalización, estabilidad política y crecimiento económico sostenido en las últimas dos décadas, miles de jóvenes se movilizaron exigiendo la gratuidad y la mejora de la calidad de la educación universitaria, en el marco de la llamada Revolución de los Pingüinos, entre los ańos 2009 y 2011 (Castells, 2015).

Y, en junio del año 2013, mientras se disputaba un torneo internacional de fútbol, emergió con vigor en Brasil el movimiento Passe livre, cuyo objeto inicial de reivindicación fue la lucha por un sistema de transporte público gratuito y de calidad, pero cuya agenda más amplia incorporó otras reivindicaciones sociales. La crítica de los jóvenes y sectores de trabajadores movilizados de Brasil hacia el gobierno del Partido Trabalhista (PT), tuvo que ver con la cuantiosa inversión en la Copa del Mundo de 2014 en perjuicio de un conjunto de necesidades sociales no atendidas (Castells, 2015).

\section{Las calles y las redes sociales como escenarios y mecanismos de movilización social: la gesta en contra de la ley Pulpin}

Desde que en agosto de 1990, el entonces ministro de Economía, Juan Carlos Hurtado Miller, anunció al país la aplicación de un programa de ajuste estructural, la política económica en el Perú transitó de un modelo de desarrollo de carácter 
estado céntrico a un modelo de corte neoliberal, en el cual el eje de crecimiento económico y de la asignación de recursos es -en teoría- el mercado y su mano invisible (Durand, 2006).

Se dio inicio entonces a un conjunto de reformas económicas orientadas a brindar condiciones favorables a los inversionistas privados, nacionales y extranjeros, a fin de que dinamicen la economía peruana y la conduzcan por la vía del crecimiento económico y su inserción en la economía global. El crecimiento económico en las últimas dos décadas ha sido, sin embargo, intermitente y desigual. Luego de las reformas, a principios de la década del 90, el Perú experimentó una importante inyección de recursos provenientes de créditos internacionales, de la venta de empresas públicas y la inversión en actividades extractivas, principalmente en el sector minero.

La primavera económica, sin embargo, no duró mucho dado que a partir del año 1997 la economía peruana -extremadamente dependiente del mercado internacional de materias primas- experimentó los impactos negativos de la llamada crisis asiática. Las cifras macroeconómicas empezarían a recuperarse a comienzos de la década siguiente, debido a la mejora de los precios de los minerales y el ciclo expansivo de la economía China. Pero, nuevamente, el ciclo de crecimiento sostenido empezó a extinguirse a comienzos de la década actual, a causa de la dinámica internacional y de la débil diversificación productiva de la economía peruana.

En el marco de la crisis, las decisiones adoptadas por el gobierno de Ollanta Humala, paradójicamente elegido por sus propuestas contrarias al modelo neoliberal, se orientaron a tratar de mejorar las condiciones para los sectores empresariales aunque ello implique un alto costo social y mayores niveles de conflictividad.

Así, en noviembre de 2014, se empieza a gestar en el seno del gobierno lo que sería una norma efímera, la ley que promueve el acceso de jóvenes al mercado laboral y a la protección social. Previamente, dos importantes gremios empresariales: la Asociación de Exportadores (ADEX) y la Sociedad
Nacional de Industrias (SIN), presentaron ante el Congreso y el propio gobierno, sendas iniciativas para "flexibilizar" el mercado laboral mediante el recorte de derechos de los trabajadores.

El Ministerio de Economía y Finanzas (MEF), empoderado a partir de la Constitución neoliberal del año 1993, promovió en el ámbito del Ejecutivo la aprobación del proyecto de ley que fue presentado al Congreso para su discusión y aprobación en tiempo récord. A través de su página Web, el MEF señalaba que:

"La Ley dará a los jóvenes la opción de un trabajo formal, en planilla, y con beneficios laborales esenciales, algo que es importante para este segmento de trabajadores porque podrán adquirir experiencia laboral, capacitarse $y$ continuar con el desarrollo de su vida laboral de forma más adecuada".

En comparación con el régimen laboral general, la norma no contemplaba el derecho a la Compensación por Tiempo de Servicios (CTS), monto que cada ańo los empleadores depositan a sus trabajadores en planilla, ni las gratificaciones de julio y diciembre. Así mismo, el período de vacaciones que bajo el régimen general es de 30 días, en la ley Pulpín era solo de 15. La ley tampoco contemplaba el monto de asignación familiar.

La norma fue considerada atentatoria contra los derechos laborales de los jóvenes y a la vez beneficiosa para las empresas, las que podían acogerse a crédito fiscal a cambio de brindar capacitación a los nuevos trabajadores.

Adicionalmente, se criticó severamente la celeridad y la opacidad del proceso seguido: la formulación del proyecto en el seno del Ministerio de Economía y Finanzas, la aprobación en el Consejo de Ministros, así como la discusión y aprobación en el ámbito del Congreso ${ }^{3}$. Así, entre los primeros días de noviembre y el 16 de diciembre, día en que se publicó la ley en el diario oficial El Peruano, se consumó una discutible reforma laboral.

Se trató de un conflicto por la pérdida de derechos económicos y sociales. En un primer mo-

\footnotetext{
2 Véase al respecto: http://www.mef.gob.pe/index.php?option=com content\&view=article\&id=3750\&Itemid=10196 4\&lang=es (Consulta: 10 de diciembre del 2015).

3 Puede verse al respecto: https://redaccion.lamula.pe/2015/01/15/cronologia-de-la-leypulpin/enriquelarrea/ (Consulta: 10 de diciembre del 2015).
} 
16 mento, pareció imponerse el interés de los principales grupos económicos del país por contar con condiciones más favorables para el desarrollo de diversas actividades empresariales a través del recorte de derechos laborales, en perjuicio de los derechos de los futuros trabajadores.

Cabe señalar, sin embargo, que, en el proceso de revisión y discusión del proyecto en el Congreso, fuerzas de oposición y sectores de sociedad civil denunciaron que la aprobación de la norma iba a significar un recorte drástico de los derechos laborales de los jóvenes. Las redes sociales en Internet, algunos espacios periodísticos y formas tradicionales de organización social fueron los principales escenarios de las críticas a la ley y de los llamados al repudio de la decisión adoptada por la mayoría de congresistas.

Una vez promulgada la ley por el presidente Ollanta Humala, el malestar entre sectores de jóvenes -universitarios y no universitarios- y de organizaciones de trabajadores se fue transformando en acciones de protesta, en un principio sin mucho nivel de organización. Se convocó así, combinando para ello los medios de comunicación convencionales y los llamados nuevos medios, a la primera manifestación pública significativa. Fue masiva y poco organizada, pero marcó un hito en una gesta social que concluyó con la derogatoria de la norma:

"La primera march a contra el Régimen Laboral Juvenil, realizada el 18 de diciembre, fue un caos total. Por un lado, la masa juvenil se desplazó por diversas calles de Lima con una organización precaria, lo que sumado a la represión policial derivó en más de una veintena de jóvenes detenidos y una cifra mayor de heridos..." (Díaz, 2015).

Jóvenes estudiantes, trabajadores y miembros de diversas organizaciones sociales y políticas de izquierda utilizaron las redes sociales de Internet -principalmente Facebook- para entrelazar voluntades y coordinar acciones públicas de protesta, en Lima y en otras ciudades del país. En el contexto de las primeras manifestaciones, diversos medios de comunicación empezaron a abrir espacios de información y opinión sobre la reacción popular en contra de la norma.

Asimismo, como en otras movilizaciones en diversas regiones del planeta, los propios manifestantes se convirtieron en una especie de reporteros ciudadanos de los acontecimientos de las marchas, alimentando el ciberespacio con imágenes, vídeos, audios y textos que generaron un contrapeso frente al silencio o los sesgos de los medios de comunicación que tienden a estigmatizar la protesta social como expresiones de violencia irracional. La represión policial, desproporcionada, fue reportada por miles de manifestantes. Funcionaron, asimismo, las alertas sobre detenciones ilegales en el marco de las movilizaciones y se activaron redes de asesoría y defensa jurídicas de los manifestantes.

En la marcha inicial y en las siguientes movilizaciones participaron sectores sociales con cierta experiencia política y de movilización social: sindicatos, organizaciones sociales de base y partidos de izquierda. También asistieron jóvenes y otros colectivos que participaron en experiencias de acción colectiva, puntuales pero intensas, de años anteriores.

Uno de los líderes de la movilización en contra de la ley Pulpín, Gabriel Salazar, afirmó en el marco de una reunión académica ${ }^{4}$, que participó conjuntamente con otros jóvenes y organizaciones de sociedad civil, en acciones similares en contra de la candidatura presidencial de Keiko Fujimori, en el año 2011, y en contra de la llamada "Repartija" en el año 2013, a raíz de una controversial decisión del Congreso respecto a la designación del Defensor del Pueblo, de miembros del Tribunal Constitucional y de integrantes del directorio del Banco Central de Reserva. A los sectores con mayor o menor experiencia en este tipo de movilizaciones, se sumaron también ciudadanos que por primera vez salían a las calles en pos de lograr un objetivo político: la derogatoria de la norma.

En la organización, convocatoria e información sobre las movilizaciones mencionadas, el uso de Internet y las redes sociales, principalmente $F a$ cebook, fue un factor importante. Ello se evidenció cuando a las protestas y llamados de diversos

4 Intervención realizada en el marco del Seminario Comunicación y Desarrollo Humano, organizado por la Facultad de Ciencias y Artes de la Comunicación de la Pontificia Universidad Católica del Perú, el 3 de junio del 2015. 
ciudadanos se articularon ciertos líderes de opinión percibidos como consecuentes con las causas sociales: periodistas, líderes sociales y algunos políticos. Asimismo, motivados en muchos casos por los contenidos multimedia de las redes, miles de jóvenes acudieron a la marcha tal vez sin estar bien informados y/o convencidos del objeto de la movilización, pero la experiencia y el contacto con colectivos de manifestantes habría resultado valioso para establecer (otros) vínculos con cuestiones políticas, en una etapa en la cual se observa una cierta despolitización de las nuevas generaciones.

Cabe señalar que la red social digital de mayor uso en el Perú es Facebook. De una población que bordea los 30 millones de personas, se estima que en el año 2015 aproximadamente 7.8 millones ingresaba a la red para postear algún contenido todos los días y 14 millones, casi el 50\% de habitantes, al menos una vez al mes. La mayoría de usuarios de la red ingresa a través de teléfonos móviles, dispositivos usados para subir texto, imágenes y vídeos sin mayor dificultad, especialmente para las nuevas generaciones socializadas en el entorno digital.

Pero, si bien las redes multimedia se constituyeron como escenario y a la vez herramientas que contribuyen a desencadenar la emergencia y el fortalecimiento de la acción colectiva, el origen del movimiento social contra la ley Pulpín se ubica en contradicciones sociales más profundas, vinculadas a la distribución de los recursos, en este caso a través del salario y otros derechos sociales cercenados por la norma.

Además, el uso intensivo de redes sociales fue antecedido y acompañado -en una relación sinérgica- por acciones de organización, coordinación y planificación cara a cara, en asambleas, reuniones y otras formas de articulación de voluntades, negociación, alianzas con otros grupos sociales, movilización y cabildeo con los partidos políticos con representación en el Congreso 5 .

Luego de la primera marcha masiva, los grupos que lideraron la convocatoria decidieron configurar una forma básica de organización y coordinación: la Coordinadora $18 \mathrm{D}$ y las zonas de Lima y Callao, basadas en criterios territoriales. Así, quienes participaron en las movilizaciones, organizados o no organizados en redes y colectivos preexistentes, pudieron sincronizar y direccionar de mejor manera sus esfuerzos en favor de la derogatoria de la ley y de la idea de empleo digno.

Las redes multimedia potenciaron las condiciones y capacidad de movilización social, se construyó una interesante conexión con medios de comunicación y se logró generar un circuito de retroalimentación y resonancia pública muy potente, pero sin que ello signifique reemplazar a los espacios y prácticas tradicionales de acción colectiva.

Las movilizaciones en contra de la ley continuaron en los primeros días de 2015 hasta que el Congreso, presionado, derogó la norma. Sin embargo, más allá de haber logrado el objetivo central de las movilizaciones, no se pudo sentar las bases para discutir una política de promoción del empleo juvenil que genere mayores oportunidades de inserción en el mercado laboral, la idea de un empleo digno en un acuerdo político para discutir una reforma sustantiva al respecto. Tampoco el Consejo Nacional del Trabajo, integrado por representantes del gobierno, del sector empresarial y de los trabajadores, ha avanzado en una discusión y generación de propuestas iniciales sobre el tema.

Como se planteó líneas arriba a partir de las ideas de Tilly (2010), los movimientos sociales pueden transitar, en términos de crecimiento o declive, hacia la institucionalización y transformación o, en sentido contrario, hacia la extinción; y en la dimensión espacial de la acción podrían ir de lo local a lo global, pasando por lo regional, nacional e internacional. Las rutas que habría tomado el movimiento social que contribuyó a derogar la llamada ley Pulpín serían la de una multiplicación y expansión a diversas ciudades (el Perú urbano) y el de la extinción, aunque la trama de colectivos y redes de jóvenes y trabajadores que posibilitó la movilización continúa con sus propias agendas y dinámicas.

\footnotetext{
5 Se podría decir, retomando las ideas de Tilly (2010), que el movimiento en contra de la ley Pulpín fue portador de los tres tipos de reivindicaciones: programáticas, identitarias y de posición.
} 


\section{Bibliografía}

En tanto nuevo ámbito de sociabilidad, conectado con los espacios e instituciones tradicionales como la familia, el ámbito educativo, el mundo laboral, los grupos de pares y los medios de comunicación convencionales (radio, prensa, televisión), Internet y las redes de comunicación se han constituido como escenarios e instrumentos que potencian las posibilidades de emergencia y acción de los movimientos sociales contemporáneos. Facilitan la construcción de identidades colectivas, basadas en problemáticas y anhelos de cambio compartidos por ciudadanos conectados en el ciberespacio.

Las redes y plataformas virtuales son vehículos de producción e intercambio de significados, especialmente para sectores jóvenes y de zonas urbanas. Permiten visibilizar actores y propuestas, enriquecerlas a través del intercambio discursivo, convocar e involucrar a otros sectores sociales rompiendo, en parte, barreras de espacio y tiempo. Posibilitan, así mismo, producir información $\mathrm{y}$ visiones alternativas a las que generan los medios considerados tradicionales, pueden incluso facilitar la interacción con la prensa, radio y la televisión y lograr así una resonancia pública mayor El uso de Internet y las redes sociales puede ser, también, un medio de construcción de (otros) vínculos de los jóvenes con la política.

No son, sin embargo, la causa que desencadena el surgimiento de los movimientos sociales (la conflictividad social) ni sustituyen formas consideradas tradicionales de organización, convocatoria e incidencia política. Más bien pueden complementarse en una relación de carácter sinérgico.

El movimiento social por la derogatoria de la ley Pulpín y por un empleo digno, se constituyó y pudo fortalecer su capacidad de convocatoria e influencia política, en parte, gracias al uso de Internet y las redes sociales, complementariamente a la implementación de otro tipo de acciones estratégicas y tácticas. Pero, el uso de las modernas tecnologías de comunicación no definió las posibilidades y límites del movimiento social en términos de su capacidad de transformación social más allá del logro coyuntural obtenido.

Cardoso, Gustavo (2011). "De la Comunicación de Masa a la Comunicación en Red: Modelos Comunicacionales y la Sociedad de Información". En: Incom UAB http://portalcomunicacion. com/uploads/pdf/51_esp.pdf (2011). "El nacimiento de la comunicación en red. Más allá de Internet y de los medios de comunicación de masas". En: Revista TELOS, Cuadernos de Comunicación e Innovación.

Castells, Manuel (2000). Movimientos sociales urbanos. México DF: Siglo XXI editores.

(2009). Comunicación y poder. Madrid: Alianza Editorial.

(2015). Redes de indignación y esperanza (segunda edición actualizada y ampliada). Madrid: Alianza Editorial.

Cohen, Jean-Louis y Arato, Andrew (2000). Sociedad civil y teoría politica. México D.F.: Fondo de Cultura Económica.

Díaz, José (2015). "Cómo se organizaron los movimientos juveniles que acabaron con la ley Pulpin”. En: La República. http://larepublica.pe/0102-2015/como-se-organizaron-los-movimientos-juveniles-que-acabaron-con-la-ley-pulpin (Consulta: 20 de diciembre del 2015).

Durand, Francisco (2006). La mano invisible en el Estado. Lima: Fundación Friedrich Ebert.

Horst, Heather (2015). "Facebook ha traido un gran cambio en las comunicaciones". En Edu (del 23 al 29 de septiembre). Lima: Pontificia Universidad Católica del Perú. 16.

La Rosa, Amaro (2014). "Comunicación para la democracia: jóvenes y movimientos sociales en la era digital". En: Apuntes de Ciencia \& Sociedad, 04(01). Pp. 118 -124.

Lynch, Nicolás (2015). "Muerta la ley Pulpin: ;Qué queda por delante?”. En Lima: Otra Mirada. http://www.otramirada.pe/muerta-la-ley-pulp\%C3\%ADn-\%C2\%BFqu\%C3\%A9-queda-por-delante- 0

Tilly, Charles (2010). Los movimientos sociales, 1768 - 2008. Desde sus orígenes a Facebook. Barcelona: Crítica.

Touraine, Alan (1999). ¿Cómo salir del liberalismo? México: Paidós. 